\title{
Economia e instituições no governo Kubitschek*
}

\author{
Economy and institutions in Kubitschek government
}

NEWTON PAULO BUENO**

JOSÉ HELENO FARO***

\begin{abstract}
RESUMO: Este artigo procura incorporar um dos avanços teóricos mais recentes da economia institucional à análise da evolução institucional do Brasil no período 1956/1961: um modelo de escolha racional endógena para a dinâmica institucional. O período Kubitschek foi escolhido porque foi um momento da nossa história recente, onde se tentou implementar mudanças institucionais significativas em nossas instituições políticas, econômicas e sociais, buscando acelerar o ritmo do processo de industrialização. As instituições implantadas, no entanto, não apresentaram a propriedade de autofortalecimento, nem no sentido fraco, nem no sentido forte (termos definidos no artigo), sendo este assunto prejudicado por processos endógenos. Esse arranjo institucional, portanto, inicialmente capaz de se sustentar em condições de rápida industrialização com relativa estabilidade de preços, foi progressivamente enfraquecido, tornando - se auto - exequível somente em condições de estagnação econômica e inflação acelerada. Por fim, argumenta-se que a análise delineada acima pode ser útil para entender um pouco melhor a natureza geral dos processos de mudança institucional.
\end{abstract}

PALAVRAS-CHAVE: Nova economia institucional; teoria dos jogos; história econômica; governo Kubitscheck; Brasil.

ABSTRACT: This paper seeks to incorporate one of the most recent theoretical progresses in institutional economics to the analysis of the institutional evolution of Brazil during the period 1956/1961: an endogenous rational choice model for institutional dynamics. The Kubitschek period was chosen because it was a moment of our recent history where it was tried to implement significant institutional changes in our political, economical and social institutions seeking to accelerate the rhythm of the industrialization process. The institutions implanted however did not present the self-reinforcement property nor in the weak sense, nor in the strong sense (terms defined in the paper), being for this subject to be undermined by endogenous processes. This institutional arrangement therefore, that was initially capable

\footnotetext{
* Realizado com apoio financeiro do CNPq.

** Departamento de Economia, Universidade Federal de Viçosa, Viçosa/MG, Brasil. E-mail: npbueno@ mail.ufv.br.

$* * * *$ Doutorando em economia matemática, IMPA - Instituto Nacional de Matemática Pura e Aplicada, Rio de Janeiro/RJ, Brasil. E-mail: jhfaro@impa.br. Submetido: novembro 2001; aceito: novembro 2002.
} 
to sustain itself in conditions of fast industrialization with relative stability of prices, was progressively weakened, becoming self - enforceable only in conditions of economic stagnation and accelerated inflation. It is argued finally that the analysis outlined above can be useful to understand a little better the general nature of the processes of institutional change. KEYWORDS: New institutional economics; game theory; economic history; Kubitscheck government; Brazil.

JEL Classification: N16; N46.

\section{INTRODUÇÃO}

O presente trabalho procura incorporar um dos recentes avanços teóricos em economia das instituições à análise do processo político brasileiro durante o período 1956/1961: modelos de escolha racional capazes de gerar dinâmica institucional endógena (características explicitadas à frente). O motivo de se empregar um modelo desse tipo é verificar se ele pode ajudar a compreender, um pouco melhor, processos históricos em que se deixa de atingir uma situação desejável para todos os agentes envolvidos não por erros grosseiros de avaliação das conseqüências das decisões tomadas, mas exatamente pelo motivo contrário, isto é, devido ao fato de os agentes agirem racionalmente. Se a interpretação possibilitada pelo modelo for julgada convincente, seguem-se implicações políticas importantes; a principal delas é a de que é possível extrair lições valiosas de experiências políticas malsucedidas, visto que o fracasso dessas experiências não pode muitas vezes ser atribuído (pelo menos não exclusivamente) a erros fortuitos, mas a comportamentos individuais que em circunstâncias semelhantes, por serem racionais, tendem a se repetir. O período do governo Kubitschek foi escolhido em razão de se tratar de um momento da nossa história recente em que se tentaram implementar mudanças significativas em nossas instituições políticas, econômicas e sociais visando a acelerar o ritmo do processo de industrialização. Inicialmente essas mudanças foram bem-sucedidas, mas passaram progressivamente a chocar-se com o aparato institucional cristalizado em torno dos interesses tradicionais de nossa sociedade, o que acabou, como se tentará mostrar, por problematizar o avanço do processo além de um certo ponto.

Colocado desta forma, o problema de pesquisa pode parecer destituído de maior interesse analítico, por partir de uma proposição que aparentemente não pode ser falseada empiricamente, visto ser possível, com base nela, justificar ex post tanto a mudança, como a inércia institucional em um dado contexto histórico. $\mathrm{O}$ objetivo deste texto é argumentar que, diferentemente do que parece à primeira vista, é possível dotar de conteúdo empírico a proposição de que as instituições existentes em uma sociedade ora induzem, ora restringem o processo de mudança institucional. Tentar-se-á mostrar, especificamente, que modelos, como o que será utilizado neste trabalho, possibilitam restringir dedutivamente o conjunto de instituições admissíveis nos processos histórico-específicos de evolução institucional e assim formular hipóteses falseáveis sobre esses processos. 
O modelo de análise a ser empregado baseia-se essencialmente na formulação de Greif $(2001,1998)$, que sintetiza algumas das principais contribuições mais recentes da nova economia institucional para a linha de pesquisa acima exposta. Os dois pilares básicos sobre os quais o modelo se assenta, e que serão observados neste trabalho, são: 1) o aparato institucional existente em cada momento histórico e que restringe ou induz o comportamento individual em certas direções é produto da ação humana dotada de propósito (o que caracteriza o modelo como de escolha racional) e 2) pelo menos em princípio, é possível associar modificações nesse aparato, isto é, associar o processo de mudança institucional a alterações nos pesos relativos desses interesses, produzidas pela própria dinâmica do sistema, isto é, assumese que o processo de mudança institucional possa ser compreendido endogenamente (embora, é claro, fatores exógenos possam alterar a qualquer momento esses pesos e, assim, o aparato institucional, mas a não ser no sentido de que esses fatores exógenos produzam mudanças na dinâmica endógena do sistema, serão desconsideradas na análise que segue as mudanças puramente exógenas).

O primeiro pressuposto acima implica que a análise deve levar em conta as interações estratégicas entre os tomadores de decisão, que se baseiam nas avaliações dos trade-offs entre as vantagens advindas do comportamento free-riding e os benefícios potenciais das soluções coletivas possíveis de serem alcançadas; dir-se-á que um arranjo institucional é auto-aplicável quando, pesando os trade-offs envolvidos, os tomadores de decisão não têm razão para alterar a institucionalidade existente. O segundo postulado, por outro lado, implica que um arranjo institucional auto-aplicável pode ser minado por processos endógenos, na medida em que os pesos relativos dos interesses envolvidos se alteram em função da própria dinâmica do processo social (ou que fatores exógenos influenciam a dinâmica endógena do sistema); neste caso se diz que o arranjo institucional estudado não apresenta uma propriedade vital para sua preservação que é a do auto-reforço.

$\mathrm{O}$ artigo está estruturado da seguinte forma: na seção 2, delineia-se o esquema geral de análise, definindo e operacionalizando os conceitos explicitados acima; na seção 3, focaliza-se o objetivo central do trabalho, estudando-se o processo de mudança institucional no período Kubitschek; procurou-se mostrar especificamente, nesta seção, que o aparato institucional vigente no período, embora inicialmente extremamente bem-sucedido em possibilitar uma aceleração do crescimento econômico, deixou de ser auto-aplicável em um número crescente de situações, sendo, assim, progressivamente minado por processos endógenos. Na seção 4, apresentase um modelo de interações estratégicas que formaliza o argumento da seção anterior; o modelo permite mostrar, especificamente, que o arranjo institucional vigente tornou-se progressivamente menos auto-aplicável, visto haver se tornado irracional do ponto de vista de cada grupo de agentes incorrer nos custos de manutenção desse arranjo, isto é, nos sacrifícios requeridos por políticas como a de estabilização proposta pelo programa Lopes-Campos. A seção conclusiva indica alguns procedimentos metodológicos necessários para utilizar o modelo de análise proposto em outros estudos de mudança institucional. 


\section{O MODELO DE ANÁLISE: DEFINIÇÕES E OPERACIONALIZAÇÃO DE CONCEITOS}

Definem-se instituições como os fatores sociais - visto que se consideram como tais apenas os fatores produzidos deliberada ou acidentalmente pela ação humana - que produzem regularidades na conduta humana coletiva. Tais fatores atuam restringindo ou motivando os indivíduos a se comportar de determinadas maneiras (que podem obviamente ser diferentes para várias culturas) quando estão envolvidas, por exemplo, relações de parentesco, relações entre devedores e credores ou entre empregados e empregadores; neste sentido, podem ser consideradas como instituições as regras culturais que regulam o casamento e que impedem a prática de incesto, os instrumentos de crédito, os tipos de contrato e as formas de resolver pendências financeiras entre as partes, assim como os tipos de relações de trabalho existentes.

As instituições constituem, assim, o que se pode denominar de capital social de uma sociedade (Putnan, 1993), no sentido de que têm (ou tiveram) um papel na coordenação das ações individuais, as quais na ausência dessa coordenação tenderiam a dar origem a comportamentos dos tipos free rider ou rent seeker. O primeiro comportamento deriva do fato de que os indivíduos preferem, agindo racionalmente, beneficiar-se de soluções coletivas sem incorrer nos custos necessários para produzir essas soluções; o segundo, do fato de que, como os benefícios individuais produzidos pela solução coletiva são normalmente reduzidos se apropriados por toda a sociedade, os indivíduos tenderão a organizar-se em grupos para se apropriar dos recursos já existentes, em vez de se associarem para produzir os bens públicos em questão. O resultado é que, como assinala Mancur OLSON em sua obra clássica (1999: p. 60), na ausência de mecanismos de coordenação, restrição ou estímulo da ação individual (o que aqui se denominou de instituições), quanto maior for o grupo de pessoas envolvido “...mais distante ele ficará de atingir um ponto ótimo de provimento do benefício coletivo, e os grupos muito grandes normalmente não conseguirão se prover, na ausência de coerção ou incentivos independentes e externos, nem sequer de quantidades mínimas do benefício coletivo".

Uma instituição, assim, só pode prevalecer quando é auto-aplicável (self-enforcing), no sentido de que ela não só atende aos interesses dos indivíduos envolvidos numa determinada relação social, mas induz outros indivíduos a adotar essa instituição como uma forma de obter uma solução cooperativa, que em geral não seria alcançada sem haver funcionado satisfatoriamente para um grupo menor, isto é, sem o exemplo prévio. Assim, por exemplo, desde os primórdios da história da humanidade quando grupos de caçadores encurralavam grandes mamíferos à beira de abismos, os benefícios do trabalho coletivo estabeleceram um ponto fundamental a favor da organização coletiva do trabalho. Não importa muito, para nossos objetivos aqui, especificar exatamente a natureza dessa solução e como ela acabou por se impor sobre as outras. O fato é que as comunidades humanas que lograram organizar-se dessa forma tiveram, sobre as demais, uma importante vantagem adaptativa, a qual ao que tudo indica contribuiu para tornar dominante 
essa forma de organização tanto pelo efeito da seleção natural, como pelo efeito da transmissão cultural para outros grupos de indivíduos.

Mas dizer que uma instituição prevalece porque atende aos interesses dos indivíduos envolvidos seria pouco mais do que um truísmo, se ao mesmo tempo essa definição não colocasse uma questão da maior importância para o processo de mudanças institucionais. A saber, por que as instituições mudam?

A explicação é que para as instituições se perpetuarem não basta que sejam autoaplicáveis. É necessário também que elas tenham a propriedade de serem autoreforçáveis (self-reinforcement). Diz-se que uma instituição apresenta essa propriedade quando suas implicações aumentam o número de situações em que a solução cooperativa que ela representa se auto-aplica. Assim uma instituição apresenta a propriedade de ser auto-reforçável quando, por exemplo, ela abre espaço para que as regularidades de comportamentos associadas possam se manifestar em outras áreas, cujos comportamentos associados eram determinados por outras instituições. O exemplo clássico é dado por North (1994: 361) que sugere que, se as instituições em uma sociedade favorecerem, por exemplo, a pirataria, os indivíduos desenvolverão as habilidades requeridas por essa prática e, assim fazendo, passarão a aplicálas em muitas outras esferas da vida além da atividade de pirataria propriamente.

Assim as soluções cooperativas quando prevalecem o fazem por serem ao menos temporariamente auto-aplicáveis. Mas, se não apresentarem a propriedade de auto-reforço, ao contrário se tenderem a provocar mudanças nos parâmetros do sistema social que tornam sua sobrevivência possível no longo prazo, o aparato institucional tende a alterar-se endogenamente. Argumentar-se-á que foi por essa razão que as mudanças institucionais implementadas pelo governo Kubitschek tornaram-se progressivamente menos eficazes em garantir o crescimento econômico e a estabilidade política, o que finalmente acabou por inviabilizar não apenas a ampliação do espaço do novo aparato institucional frente às instituições tradicionais, mas sua própria sobrevivência.

\section{O GOVERNO KUBITSCHEK}

Em texto clássico de 1976, Prebish registrou que nos países latino-americanos tende a haver um "descolamento" entre o processo político e o econômico. Isso tende a acontecer, segundo ele, porque a acumulação de capital é, nesses países, cronicamente insuficiente para absorver a maioria da população em empregos de maior produtividade, mas a urbanização e a difusão dos modernos meios de comunicação criavam as condições para a politização dos segmentos excluídos. A acumulação de capital tende a ser insuficiente devido à forma de utilização do excedente em nossas sociedades. Esse excedente, que já não é muito elevado, devido ao desenvolvimento insuficiente da produtividade, é gasto em sua maior parte na imitação dos padrões de consumo dos países desenvolvidos; tem-se aí então um processo que se auto-reforça, no sentido de que a acumulação de capital é insuficiente porque o excedente é pequeno e, devido a ser este gasto majoritariamente 
em consumo de luxo (pelos segmentos de renda superiores), o excedente é insuficiente para incorporar segmentos crescentes da população (e assim aumentar a produtividade média da economia) porque a acumulação de capital é reduzida.

As instituições políticas do regime populista brasileiro, para limitarmo-nos ao caso que interessa aqui, são assim auto-aplicáveis no início do período de industrialização, na década de 1930, e continuam a sê-lo durante algum tempo. Mas, na medida em que aumenta o grau de complexidade da sociedade, aumentando por exemplo a expressão numérica e política dos extratos médios, torna-se cada vez mais problemático equacionar os interesses dos segmentos tradicionais e dos associados à industrialização. As instituições do regime populista, o regime sindical, por exemplo, começam então a ser minadas endogenamente, até o momento em que se atinge um ponto de bifurcação em que ou se adapta o processo econômico em favor do avanço democrático, ou sacrifica-se este último em benefício do processo econômico e da manutenção da sociedade de consumo (Prebish, 1976: 57).

A adaptação do processo econômico, entretanto, requereria redefinir, ao nível político, uma série de regras (instituições) que regem por exemplo a distribuição do poder político e da riqueza na sociedade. Ocorre que os setores que estariam em condições de fazê-lo ou não têm interesse nisso, como os setores de classe média comprometidos com a sociedade de consumo, ou não têm as condições políticas para tanto, como os grupos excluídos. As instituições do regime populista, em outras palavras, tornam-se auto-aplicáveis a um número cada vez menor de situações, mas não emergem outras que possam ocupar o vácuo nas situações em que elas não se aplicam ou deixam de aplicar-se; a sugestão desse trabalho é que foi exatamente isso o que aconteceu na última fase do regime populista a partir da posse de Kubitschek.

Do ponto de vista estritamente econômico, o governo Kubitschek foi, como se sabe, um sucesso, promovendo uma extraordinária expansão da base industrial e uma apreciável elevação dos níveis de renda per capita ${ }^{1}$. O grande mérito de Kubitschek no processo foi o de administrar, digamos assim, um aparato institucional, desenhado numa primeira fase da industrialização brasileira pelo governo Vargas, que já não representava uma solução auto-aplicável para o problema da cooperação em uma fase mais avançada do processo. A política de Kubitschek consistiu então em "esticar" ao limite o potencial de regulação institucional do sistema getulista, rearranjando de forma ad hoc esse sistema de modo a encontrar alguma coisa para cada agente econômico fundamental.

Para o Setor Industrial, uma política generosa de crédito e a promessa de mercados internos em crescimento impulsionados por uma política fiscal expansionista; para o Setor Agro-Exportador, a manutenção da política de aquisição dos excedentes financiada por meio de emissões de moeda ${ }^{2}$ e, para os trabalhadores

\footnotetext{
${ }^{1}$ Skidmore (1992: 204).

${ }^{2} \mathrm{O}$ volume anual de compras dos estoques excedentes de café é de três a quatro vezes superior aos gastos anuais com a construção de Brasília, a meta síntese do governo Kubitschek (Orenstein e Sochaczewski, 1990: 191).
} 
urbanos, a preservação em certa medida do poder de compra do salário mínimo assegurada por uma política salarial generosa ainda que cautelosa.

Até os interesses organizados em torno da burocracia estatal foram compensados por eventuais perdas devido à criação de novas agências governamentais; assim, em vez de simplesmente extinguir organismos estatais ineficientes e caros, Kubitschek os manteve, criando uma administração paralela para realizar de forma mais eficaz as tarefas que os primeiros eram incapazes de cumprir. Essa administração paralela foi composta por novos órgãos como a Sudene, os Grupos Executivos, os Grupos de Trabalho e o Conselho de Política Aduaneira ou atribuindo mais recursos e responsabilidades aos órgãos eficientes já existentes como a Cacex, o BNDE e a Sumoc. A administração paralela era, portanto, como lembra Benevides (1990: 324), um esquema racional de gestão da política desenvolvimentista, que evitava o imobilismo do sistema sem ter que contestá-lo radicalmente.

A natureza precária desse rearranjo institucional expressou-se praticamente desde o início na dificuldade de financiá-lo. Além da proliferação de agências públicas, o que na prática inviabilizava um mínimo de controle orçamentário, a estratégia de desenvolvimento não contava nem mesmo com uma definição mínima de mecanismos de financiamento necessários para viabilizar um conjunto tão ambicioso de objetivos como os sintetizados no Programa de Metas.

As previsões otimistas sobre a evolução das contas externas, que vagamente se supunha, seriam suficientes para o financiamento do programa, frustraram-se rapidamente, com o surgimento de déficits significativos em conta corrente já a partir de 1957, embora o Brasil só viesse a se deparar com problemas de financiamento externo desses déficits no final de 1958. Quanto às fontes internas de financiamento, as estimativas de disponibilidades eram ainda mais irrealistas. Por exemplo, acreditava-se que a construção de Brasília acabaria por financiar-se a si própria, ao induzir, via a abertura de estradas para a nova capital, o aproveitamento de terras cultiváveis no Centro-Oeste, o que aumentaria substancialmente o excedente agrícola exportável. Isso de fato viria a acontecer, mas muito depois do previsto e certamente não a tempo de ajudar a financiar o rearranjo institucional denominado na literatura pelas razões apontadas acima de "Estado de Compromisso".

$\mathrm{O}$ resultado da disparidade entre as despesas orçamentárias que a manuten-ção do Estado de Compromisso requeria e a disponibilidade de recursos para financiá-las foi, naturalmente, a expansão do meio circulante e a aceleração inflacionária. O programa de estabilização Lopes-Campos foi a solução, ainda que relutante, que Kubitschek tentou dar às crescentes contradições enfrentadas pela sua estratégia de desenvolvimento. Mas, assim como o Plano Trienal de Santiago Dantas-Celso Furtado no governo João Goulart, o programa dificilmente poderia funcionar em razão de não ser, segundo a terminologia adotada neste trabalho, auto-aplicável.

É defensável que o programa Lopes-Campos pudesse ajudar a contornar a virtual asfixia cambial e a aceleração inflacionária do período. O fato é que, embora ele pudesse representar uma solução cooperativa para as dificuldades macroeconômicas, não tinha consistência do ponto de vista microeconômico. Ou seja, 
não era de interesse de nenhum dos principais agentes econômicos incorrer nos custos individuais que o programa necessariamente implicava; esses agentes até poderiam aceitar as medidas de estabilização preconizadas, mas apenas se eles pudessem se comportar como free riders.

Assim é que as tentativas de limitação do crédito industrial levantaram uma tal reação do empresariado paulista, que o Banco do Brasil decidiu, no final de 1958 , não cortar o crédito às indústrias, deixando clara a incapacidade do Ministério da Fazenda de implementar as medidas previstas no programa de estabilização. A mesma reação ocorreu por parte dos cafeicultores quando, na mesma época, Lucas Lopes tentou implementar políticas mais limitadas de apoio ao setor do que a de compra de excedentes. O próprio governo, finalmente, não estava disposto a comprometer seu programa de metas, reduzindo os investimentos governamentais, assim como não se arriscaria a perder legitimidade entre os trabalhadores adotando uma política salarial mais cautelosa.

O arranjo institucional do assim chamado "Estado de Compromisso" havia alcançado o seu limite: ele não mais era capaz de fornecer uma solução consistente para o problema da cooperação, assegurando simultaneamente a manutenção do crescimento econômico e a estabilidade de preços. Isto é, ele poderia ser preservado apenas se o governo abandonasse um desses dois objetivos ou os dois; nos termos desse trabalho, portanto, as instituições existentes tornaram-se auto-aplicáveis para um número menor de situações do que antes, sendo assim minadas (endogenamente) suas bases sustentação. $\mathrm{O}$ recurso final de ruptura com o FMI, como uma tentativa de encontrar uma solução exógena para um arranjo institucional que endogenamente já esgotara seu potencial de regulação social, reduziu ainda mais o número de situações em que suas instituições funcionariam de forma razoavelmente satisfatória, a saber sacrificando não apenas a estabilidade de preços, mas também o crescimento econômico futuro.

O governo Kubitschek assim foi capaz de criar as instituições que garantiram cinco anos de estabilidade política e de crescimento econômico; esse arranjo institucional, no entanto, como assinala Benevides (1976), era instável, no sentido de que a própria lógica do modelo de desenvolvimento comprometia progressivamente a eficácia dele. Nos termos do presente trabalho, as instituições criadas para implantar o Programa de Metas - como a administração paralela que representava um esquema gerencial racional dentro da lógica do sistema - não eram auto-reforçáveis, já que dificilmente poderiam ser estendidas para outras esferas da política global do governo e da própria sociedade porque se chocariam com as instituições correspondentes aos interesses tradicionais, que mantiveram seu peso na formulação da política pública durante todo o período. Mais ainda, na medida em que as inconsistências entre as metas e a fontes de financiamento se tornavam mais explícitas, o que se expressava diretamente na aceleração inflacionária, essas instituições passavam a ser auto-aplicáveis a um número menor de situações como mencionado acima, isto é, o aparato institucional enfraquecia-se por processos endógenos.

$\mathrm{Na}$ ausência de um aparato institucional competitivo que pudesse ocupar o 
vácuo crescente deixado pelo modelo de Kubitschek, abriu-se espaço então para propostas de mudança institucional que jamais foram de fato factíveis, dados os interesses em jogo na sociedade brasileira, e que acabaram por conduzir o país ao beco sem saída político que possibilitou o golpe militar.

\section{UM MODELO DE INTERAÇÃO ESTRATÉGICA PARA O JOGO DE INTERESSES DURANTE A TENTATIVA DE IMPLANTAÇÃO DO PROGRAMA LOPES-CAMPOS}

O modelo abaixo, na forma de um jogo estático com conhecimento perfeito,pretende esclarecer as interações estratégicas entre os principais agentes sociais que se seguiram à tentativa do governo Kubitschek de implementar o programa LopesCampos. Este programa, como já mencionado, visava garantir a estabilidade econômica e política, consideradas então ameaçadas pela aceleração da inflação e pelo agravamento da restrição externa. Uma condição para o sucesso do plano, como também assinalado na seção anterior, era que os agentes relevantes cooperassem aceitando uma diminuição na disponibilidade de crédito aos respectivos setores, o que implicaria uma política monetária restritiva. A modelagem a seguir confirma a conclusão heurística obtida na seção anterior, a saber: a de que o fracasso do plano Lopes-Campos pode ser atribuído ao fato de que ele não era auto-aplicável, no sentido de atender aos interesses de agentes individuais agindo racionalmente.

O objetivo central, ao se propor um modelo de comportamento racional a partir da teoria de jogos não cooperativos, é encontrar soluções de equilíbrio para uma situação de escolha individual em condições de interação estratégica, isto é, soluções para o jogo. Vale ressaltar que, como em qualquer modelo, o equilíbrio é definido como um conjunto de crenças e estratégias tal que, dadas suas crenças, a estratégia de cada agente é a que lhe garante maior utilidade ex ante, dentre os cursos de ação factíveis. O conceito de equilíbrio de Nash impõe que as crenças de cada jogador sejam consistentes com as estratégias dos demais agentes. Assim, para a modelagem é necessário especificar os jogadores, suas opções estratégicas, as crenças envolvidas no jogo, além das preferências que os agentes possuem sobre os possíveis resultados do jogo.

(i) Jogadores: Os agentes participantes do jogos são o Governo Kubitschek, o Setor Industrial e o Setor Agro-Exportador (deixa-se de considerar os trabalhadores não apenas por conveniência de exposição, mas porque se considera que sua atuação não tenha sido decisiva para explicar o fracasso do plano de estabilização).

(ii) Opções Estratégicas: Para cada agente tem-se um conjunto de possíveis ações especificadas como segue abaixo:

a) Para o Governo: este pode tentar implementar o plano de ajusteeco- 
nômico (A) ou simplesmente não fazê-lo — ou desistir de implementálo - (NA): neste último caso o jogo "acaba".

b) Para o Setor Industrial: caso o governo tente implementar o plano, este setor pode cooperar $(\mathrm{C})$, o que significa aceitar as restrições na política monetária, ou não cooperar (NC) ao não aceitar as reduções na disponibilidade de crédito para o setor.

c) Para o Setor Agro-Exportador: dada a proposta de ajuste anunciada pelo governo, este setor pode cooperar $(\mathrm{C})$, ao aceitar uma política de valorização do café mais tímida que uma política monetária mais restritiva implicaria ou não cooperar (NC) ao impor a continuidade da conduta até então praticada pelo governo.

(iii) Crenças: Uma hipótese central do modelo é a crença, por parte dos jogadores, de que o ajuste será alcançado se, e somente se, o Setor Agro-Exportador agir de forma cooperativa, na medida em que, embora o setor não tenha um papel decisivo para o sucesso da industrialização, absorve parcela substancial dos recursos necessários para financiar o processo.

(iv) Preferências: Cada jogador apresenta uma relação de preferência sobre oconjunto de resultados factíveis. Do que foi exposto anteriormente, têm-se os seguintes possíveis resultados:

a) O governo decide não implementar o plano de estabilização.

b) O governo decide tentar implementar o plano, seguindo-se quatro possíveis situações dependendo do comportamento dos setores Industrial e Agro-Exportador. São estas: a cooperação bilateral, a não-cooperação bilateral ou uma cooperação unilateral por parte de um dos setores. Logo, temos como conjunto de resultados factíveis:

$R=\{(N A, \bullet, \bullet),(A, C, C),(A, C, N C),(A, N C, C),(A, N C, N C)\}$

As relações de preferências para cada jogador são definidas do seguinte modo:

(1) Preferências do Governo. Denota-se por $>_{G}$ a relação de preferência do governo sobre $\mathrm{R}$.

Pressupõe-se a seguinte ordenação das opções disponíveis:

$$
(A, C, C)>_{G}(A, N C, C)>_{G}(N A, \bullet, \bullet)>_{G}(A, N C, N C)>_{G}(A, C, N C)
$$

Tal ordenação reflete:

- $(A, C, C)>_{G}(A, N C, C)$. Dado o comportamento cooperativo do Setor AgroExportador, em ambos os casos tem-se o sucesso do plano de ajuste. Todavia, no segundo caso a cooperação unilateral implica descontentamento por parte do Setor Agro-Exportador, o que compromete o apoio político do setor ao governo na sucessão presidencial.

- $(A, N C, C)>_{G}(N A, \bullet, \bullet)$. No primeiro resultado tem-se o sucesso do plano apresentado e manutenção do ritmo de industrialização. O outro resultado implica um descontrole dos fundamentos macroeconômicos; este ambiente é inapropriado para o Setor Industrial, dadas as incertezas oriundas do descontrole da inflação e 
do câmbio, além de provocar um descontentamento político por parte do Setor AgroExportador o qual veria o governo com um perfil incapaz de satisfazer seus interesses e conduzir a economia com sucesso relativo.

- $(N A, \bullet, \bullet)>_{G}(A, N C, N C)$. Em ambos os casos ocorrem a desorganização dos fundamentos macroeconômicos e a conseqüente perda de legitimidade política, mas no segundo caso ocorre ainda o desgaste político do governo ao propor um plano sem credibilidade.

$-(A, N C, N C)>_{G}(A, C, N C)$. Diante do fracasso causado pelo comportamento não cooperativo do Setor Agro-Exportador, o governo prefere que o Setor Industrial continue tendo incentivos.

(2) Preferências da Indústria. Denota-se, respectivamente, por $>_{I}$ e por $\approx_{I}$ as relações de preferência e indiferença da indústria sobre $R$. Tem-se a seguinte ordenação das opções disponíveis:

$$
(A, N C, C)>_{I}(A, C, C)>_{I}(N A, \bullet, \bullet) \approx_{I}(A, N C, N C)>_{I}(A, C, N C)
$$

Tal ordenação reflete:

- $(A, N C, C)>_{I}(A, C, C)$. Dada a suficiência da cooperação por parte do Setor Agro-Exportador para o sucesso do plano de ajuste, a industria obterá um maior pay-off se puder se esquivar de partilhar os custos da solução cooperativa, isto é, tem-se aqui a possibilidade de um comportamento free rider por parte da indústria (o Setor Agro-Exportador não pode adotar um comportamento free rider, pois os agentes sabem que a solução cooperativa não pode ser alcançada sem a cooperação desse setor - ver tópico iii).

$-(A, C, C)>_{I}(N A, \bullet, \bullet) \approx_{I}(A, N C, N C)$. Dentre a segunda e terceira possibilidade a indústria não obtém alterações em seu pay-off, pois nos dois casos têm-se as mesmas implicações. Mas a primeira opção é preferível, pois a cooperação bilateral implica manter o processo de industrialização.

$(A, N C, N C)>_{I}(A, C, N C)$. Em ambos os casos, tem-se o insucesso do plano, sendo que, na primeira possibilidade, observa-se a continuidade da política de incentivos à indústria.

(3) Preferências do Setor Agro-Exportador. Denota-se, respectivamente, por $>_{A E}$ e por $\approx_{A E}$ as relações de preferência e indiferença do Setor Agro-Exportador sobre $R$. Tem-se a seguinte ordenação das opções disponíveis:

$$
(A, C, C)>_{A E}(A, C, N C)>_{A E}(N A, \bullet, \bullet) \approx_{A E}(A, N C, N C)>_{A E}(A, N C, C)
$$

Tal ordenação reflete:

- $(A, C, C)>_{A E}(A, C, N C)$. Diante da cooperação por parte da indústria, o Setor Agro-Exportador prefere cooperar, dada a impossibilidade de sucesso de plano diante de sua não-cooperação, isto é, este não pode assumir um comportamento free rider. A cooperação conjunta é desejável porque implica um ambiente político-econômico mais estável, em que esse setor pode manter seu poder político na sociedade.

- $(A, C, N C)>_{A E}(N A, \bullet, \bullet) \approx_{A E}(A, N C, N C)$. Pelos mesmos motivos expostos para a indústria, a segunda e terceira opções não implicam pay-offs distintos para 
o Setor Agro-Exportador. O primeiro caso, como os dois seguintes, implica o não-ajuste da economia, todavia, neste caso o Setor Agro-Exportador obtém a prioridade na política de incentivos do governo, enquanto nos demais este tem que se contentar em dividir os recursos.

$-(A, N C, N C)>_{A E}(A, N C, C)$. Tal preferência reflete a indisposição do Setor Agro-Exportador em perder poder político-econômico. O que seria evidenciado caso o governo implementasse um plano em que somente este setor cooperasse.

(v) Árvore do Jogo e Matriz de Pay-Offs.

O jogo modelado abaixo tem como características ser estático e com informação perfeita. Os pay-offs são apresentados com números, o que é conveniente por facilitar a compreensão do leitor; esses números, entretanto, são escolhidos de forma que seja respeitada a ordenação correta das preferências anteriormente expostas. Observe-se ainda que tal representação está de acordo com o resultado conhecido da teoria da escolha do consumidor de que toda relação de preferência sobre um conjunto finito tem uma função de preferência a valores reais, que é única, a menos de uma transformação monotônica.

A árvore do jogo é a seguinte:

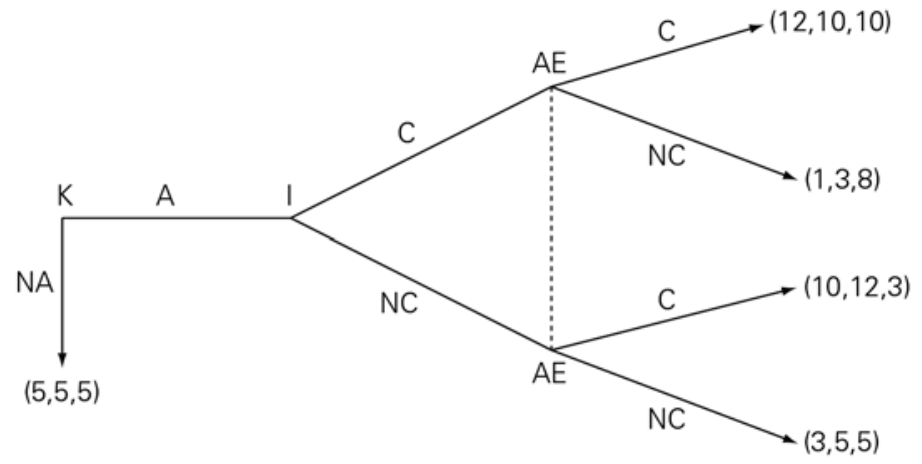

O subjogo dado a partir da ação "A", por parte do governo, pode ser apresentado na forma estratégica abaixo:

\begin{tabular}{|c|c|c|c|}
\hline & \multicolumn{3}{|c|}{ AE } \\
\hline & & $C$ & NC \\
\hline 1 & $C$ & $(10,10)$ & $(3,8)$ \\
\hline & NC & $(12,3)$ & $(5,5)$ \\
\hline
\end{tabular}

I: Setor Industrial e AE: Setor Agro-Exportador.

Pode-se ainda visualizar a dinâmica da escolha das ações por parte de jogadores a partir do gráfico abaixo: 


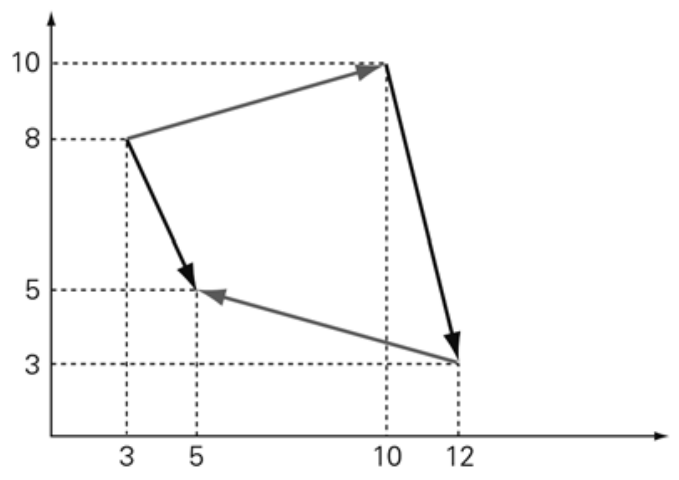

em que a linha cinza contínua indica a tendência de ação por parte do Setor AgroExportador e a linha preta contínua indica a tendência de ação por parte da indústria.

Conclui-se então que o único equilíbrio de Nash, para o subjogo exposto na forma estratégica (tabela), é a solução não cooperativa, assinalada em negrito (nesta situação, uma vez alcançada, os agentes não terão razão para alterar suas estratégias).

Retomando o jogo na forma extensiva, entretanto, vê-se que o equilíbrio de Nash para esse jogo é dado pela solução em que o governo não propõe o plano de ajuste ou desiste de implementá-lo. Isso foi o que de fato acabou por ocorrer implicando a aceleração da inflação e a asfixia cambial, a qual obrigou o governo a decretar moratória internacional em 1959.

\section{CONCLUSÃO}

Procurou-se mostrar neste trabalho que modelos baseados na nova economia institucional permitem restringir dedutivamente o espaço de mudança institucional admissível para as sociedades em cada período histórico; para realizar estudos aplicados baseados nesses tipos de modelo, parece recomendável seguir os seguintes procedimentos básicos:

1. Estudo das propriedades de auto-aplicação de um certo arranjo institucional,considerando os quase parâmetros como fixos e exógenos. O objetivo nesta etapa será identificar em que medida o aparato institucional permite aos agentes sociais realizar seus objetivos individuais simultaneamente e de maneira concomitante à obtenção da solução cooperativa que se tem em mente.

2. Exame dos processos de auto-reforço implicados pelo arranjo institucional.O objetivo aqui é tentar entender se as regularidades de comportamento que esse arranjo induz para cada grupo de agentes sociais estimulam ou desestimulam a adoção desses comportamentos pelos demais. Se os comportamentos induzidos tendem a se generalizar por meio de processos endógenos, 
pode-se supor que as instituições que os induzem apresentam a propriedade fraca de auto-reforço. Se, ao contrário, parecer provável que tais comportamentos se choquem com comportamentos cristalizados antagônicos suficientemente fortes, poder-se-á concluir que o arranjo institucional sob análise acabará por ser minado pelas instituições preexistentes, sendo o ritmo de mudanças interrompido pela inércia institucional do sistema.

3. Exame das implicações de longo prazo de um arranjo institucional. Nestaetapa final se procurará entender como esse arranjo altera os próprios parâmetros institucionais do sistema. Assim, enquanto as duas etapas anteriores supõem o meio ambiente institucional como dado, aqui se permite que os comportamentos individuais alterem os próprios dados do problema. Por exemplo, que novos agentes sociais o arranjo institucional analisado coloca em cena no longo prazo? Como ele altera a distribuição do poder político e econômico na sociedade? Esta etapa difere da anterior na medida em que não se questiona se os comportamentos induzidos pelo novo arranjo institucional analisado podem ou não se generalizar pelo sistema social preexistente, mas se tais comportamentos são potentes $o$ suficiente para produzir mudanças no próprio sistema social, as quais incluirão esses comportamentos como instituições auto-aplicáveis. Neste caso se dirá que o arranjo institucional apresenta a propriedade forte de auto-reforço.

Com o objetivo de ilustrar a seqüência de procedimentos acima, retomemos rapidamente o estudo sobre o governo Kubitschek realizado na seção anterior, colocando-o na forma sugerida acima. O arranjo institucional alcançado pode ser considerado, graças em boa parte à habilidade conciliatória de Kubitschek, como auto-aplicável. Isso pode soar um pouco estranho, porque certamente dependeu da feliz coincidência de haver um presidente suficientemente habilidoso para implementá-lo; como definido anteriormente, entretanto, o termo auto-aplicável significa aqui que o arranjo atendia aos interesses individuais imediatos dos principais agentes sociais.

As instituições do período, entretanto, não apresentavam a propriedade de autoreforço no sentido fraco, visto que se deparavam com, digamos assim, uma fronteira institucional representada pelas instituições tradicionais, por exemplo, os organismos estatais preexistentes e o sistema parlamentar comprometido com a política de clientela vigente, que a prática da administração paralela contornava, mas não contestava radicalmente.

$\mathrm{O}$ arranjo institucional do governo Kubitschek, finalmente, não apresentava a propriedade de auto-reforço no sentido forte, estando assim sujeito a ser minado por processos endógenos. Isso ocorria porque as mudanças nos parâmetros que as novas instituições implicavam no longo prazo reduziam o número de situações em que esse arranjo institucional era capaz de fornecer uma solução para o problema da cooperação na sociedade brasileira de então. Assim o arranjo era inicialmente capaz de sustentar-se em termos políticos simultaneamente a um processo de industrializa- 
ção rápida com relativa estabilidade de preços. Numa segunda fase, ainda foi possível contornar as inconsistências crescentes entre as metas desenvolvimentistas - $\mathrm{o}$ output do processo - e os recursos necessários para obtê-las — os inputs -, mas com inflação crescente. A evolução deste último quase parâmetro, por fim, acabou por dificultar o acesso aos recursos externos que financiavam até então o Programa de Metas e asseguravam a manutenção do crescimento econômico.

A conclusão é a de que o arranjo institucional populista irá ter uma sobrevida durante os governos Jânio Quadros e João Goulart, mas com uma margem de manobra muito menor do que no período Kubitschek. Isto é, ele tornou-se auto-aplicável somente em condições de estagnação econômica e inflação acelerada.

O esquema análise apresentado, embora conduzindo a conclusões que parecem não contradizer a essência do processo estudado, é obviamente ainda bastante rudimentar; a modelagem apresentada na seção 4 sugere como passar desse nível essencialmente heurístico de análise para estudos formalmente mais rigorosos e passíveis de refutação empírica mais conclusiva.

\section{REFERÊNCIAS}

ABREU, M. P. (1992) A Ordem do Progresso. Rio de Janeiro: Campus.

BENEVIDES, M. V. M. (1976) O Governo Kubitschek - Desenvolvimento Econômico e Estabilidade Política. Rio de Janeiro: Paz e Terra.

GREIF, A. (2001) "Institutions and Endogenous Institutional Change: Historical Institutional Analysis”. Campinas: II Seminário da Nova Economia Institucional/Unicamp, março.

GREIF, A. (1998) "Self-enforcing Political Systems and Economic Growth". In: BATES et al., Analytic Narratives. Princenton: Princenton University Press.

NORTH, D. (1994) “Economic Performance Through Time”. The American Economic Review, vol. 84 (3), june 1994.

ORENSTEIN, L. e SOCHACZEWSKI, A. C. (1990). “Democracia com Desenvolvimento”. In: ABREU, M. P. A., Ordem do Progresso. Rio de Janeiro: Ed. Campus.

PREBISH, R. (1976) “Critica al capitalismo periférico”. Revista de la CEPAL, primer semestre.

PUTNAM, R. (1993) Making Democracy Work - Civic Traditions in Modern Italy. Princeton: Princeton University Press.

SKIDMORE, T. (1992). Brasil: de Getúlio a Castelo. Rio de Janeiro: Paz e Terra. 